\title{
Disconnected pancreatic duct syndrome - Wait! Why not try one more time?
}

A 42-year-old man with a history of necrotizing pancreatitis complicated by pancreatic fluid collections (PFCs) who underwent percutaneous drainage for 4

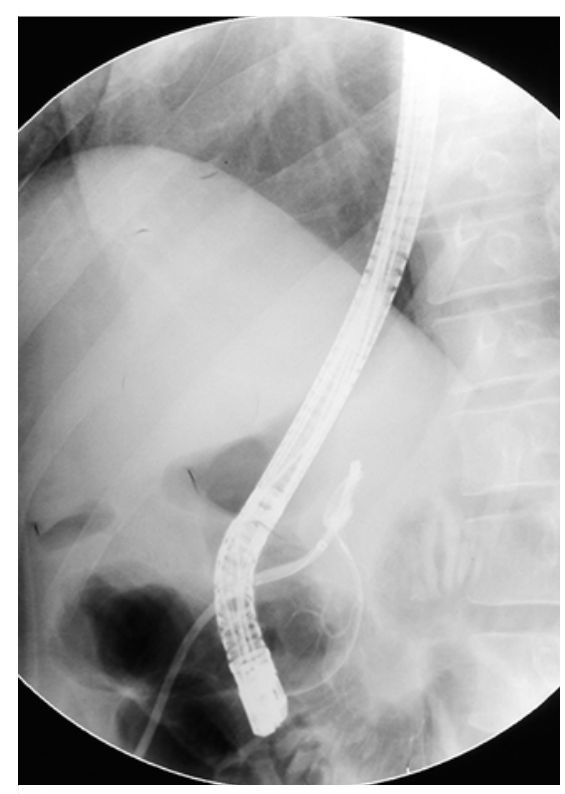

> Fig. 1 Image from an endoscopic retrograde cholangiopancreatography performed at another endoscopy center suggesting there was complete main pancreatic duct disruption. months but still had a persistent external fistula with high amylase activity in the drainage fluid was referred. A previous endoscopic retrograde cholangiopancreatography (ERCP) in another endoscopy center had suggested complete main pancreatic duct (MPD) disruption ( Fig. 1). Contrast injection through the drainage catheter showed no opacification of the proximal MPD ( $\mathbf{F i g . 2 a )}$. During a second ERCP, carried out in our endoscopy center, contrast injection through the major duodenal papilla also demonstrated complete cutoff of the proximal MPD and no opacification of the distal MPD ( $\triangleright$ Fig. $\mathbf{2 b}$ ). Therefore, the diagnosis of complete MPD disruption was made and normally surgical treatment would have been considered.

Fortunately, in this case, after several attempts by the endoscopist, the disruption site was traversed with a guidewire, and the route from the MPD complete cutoff to the site of the PFCs was not opacified by any contrast. A pancreatic stent was placed to drain the PFCs ( $\triangleright$ Fig. 2c and - Fig. 3; - Video 1) and immediately there was cessation of fluid drainage from the percutaneous drainage catheter. The patient had an uneventful recov- ery and was discharged 1 day later, with surgery having been avoided.

The diagnosis of disconnected pancreatic duct syndrome (DPDS) is usually confirmed on ERCP if there is extravasation of injected contrast from the MPD without filling of the distal MPD [1]. Once the diagnosis of complete MPD disruption has been made, it is often treated by surgery [2], while endotherapy is effective for partial pancreatic ductal disruption [3]. However, we have shown in this case, where both percutaneous and endoscopic contrast injection had demonstrated complete cutoff of the pancreatic duct, that there is still a possibility that the guidewire may cross the site of the disruption and that a stent can be placed to drain the pancreatic juice or PFC. But only if we try!

Endoscopy_UCTN_Code_TTT_1AR_2AI

\section{Acknowledgment}

Dr. Yu Bai is supported by the National Natural Science Foundation of China (Grant No. 81670473) and National Key R\&D Program of China (2017YFC1308800) and Three Engineering Training Funds in Shenzhen (No. SYLY201718).
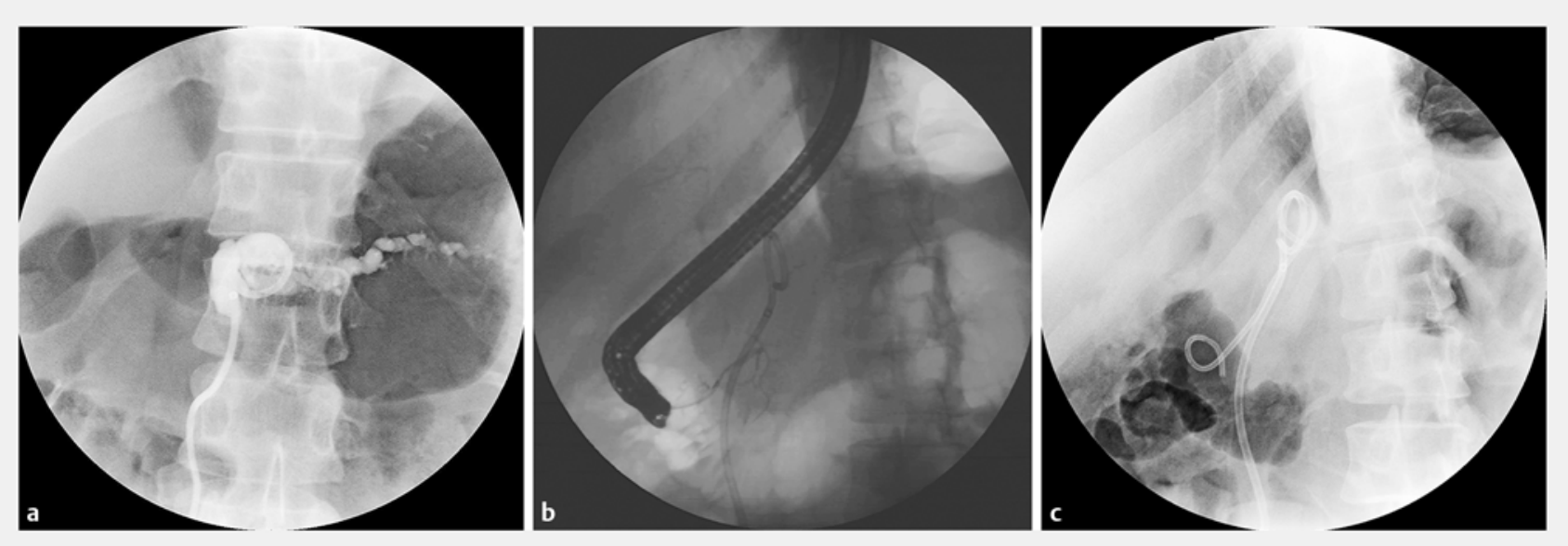

Fig. 2 Radiographic images showing: a no opacification of the proximal main pancreatic duct (MPD) on contrast injection through the drainage catheter; $\mathbf{b}$ complete cutoff of the proximal MPD and no opacification of the distal MPD on contrast injection through the major duodenal papilla; $\mathbf{c}$ a pancreatic stent placed to drain the pancreatic fluid collections. 


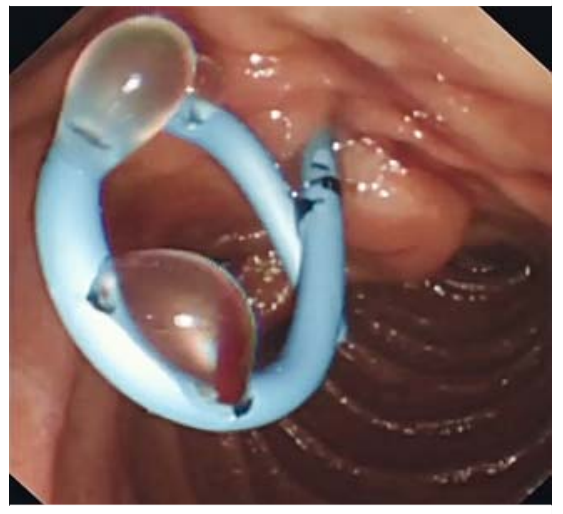

Fig. 3 Endoscopic image showing pancreatic juice draining through the stent.

\section{Competing interests}

\section{None}

The authors

Shu-Ling Wang*, Sheng-Bing Zhao*, Tian Xia, Zhao-Shen Li, Yu Bai

Department of Gastroenterology, Changhai Hospital, Second Military Medical University, Shanghai, China

\section{Corresponding author}

\section{Yu Bai, MD, PhD}

Department of Gastroenterology, Changhai Hospital, Second Military Medical University, Shanghai, China

baiyu1998@hotmail.com

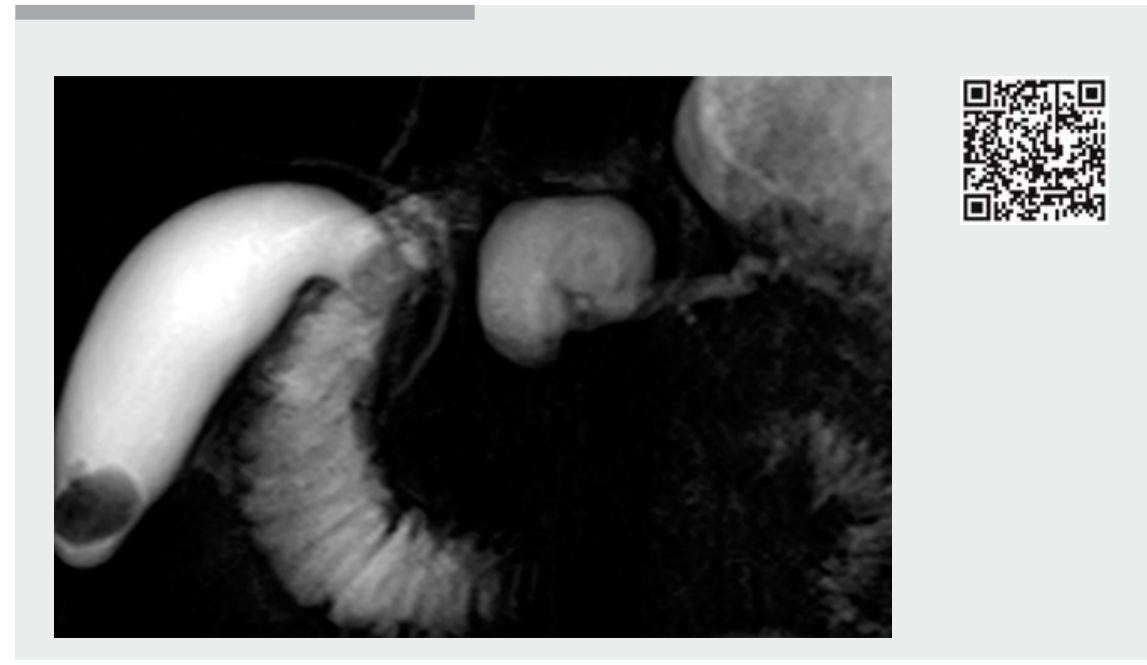

Video 1 Endoscopic retrograde cholangiopancreatography treatment of disconnected pancreatic duct syndrome.

\section{References}

[1] Nadkarni NA, Kotwal V, Sarr MG et al. Disconnected pancreatic duct syndrome: endoscopic stent or surgeon's knife? Pancreas 2015; 44: 16-22

[2] Jang JW, Kim MH, Oh D et al. Factors and outcomes associated with pancreatic duct disruption in patients with acute necrotizing pancreatitis. Pancreatology 2016; 16: 958 965

[3] Das R, Papachristou GI, Slivka A et al. Endotherapy is effective for pancreatic ductal disruption: A dual center experience. Pancreatology 2016; 16: 278-283

\section{Bibliography}

DOI https://doi.org/10.1055/a-0605-3076

Published online: 12.6.2018

Endoscopy 2018; 50: E188-E189

(c) Georg Thieme Verlag KG

Stuttgart · New York

ISSN 0013-726X

\section{ENDOSCOPY E-VIDEOS}

https://eref.thieme.de/e-videos

口回 Endoscopy E-Videos is a free access online section, reporting 自链 on interesting cases and new techniques in gastroenterological endoscopy. All papers include a high quality video and all contributions are freely accessible online.

This section has its own submission website at https://mc.manuscriptcentral.com/e-videos

\footnotetext{
* Contributed equally to this work
} 